\title{
A Case Report on Chylolymphaticus Variety of Mesenteric Cyst
}

\author{
S SHARMIN ${ }^{\mathrm{a}}$, D ALAM ${ }^{\mathrm{b}}$, MM RAHMAN $^{\mathrm{c}}$, S NARGIS $^{\mathrm{d}}$
}

\begin{abstract}
Summary:
Mesenteric cyst is rare with a variable clinical presentation. The clinical presentation is not characteristic and the preoperative imaging although suggestive but not diagnostic. In most cases, the diagnosis is confirmed following surgical exploration. We report a case of chylolymphaticus variety of mesenteric cyst in18-year-old girl, who was presented to us with diffuse abdominal pain and lump in the lower abdomen for 14 days. Ultrasonography (USG) of the abdomen revealed large cystic lesion $(12 \times 10.8 \times 11.4 \mathrm{~cm}$, volume $77 \mathrm{cc})$ in the
\end{abstract}

\section{Introduction :}

A Chylolymphatic cyst is a rare variant of a mesenteric cyst ${ }^{1,2}$. These cyst present within the mesentery lined with a thin endothelial or mesothelium and filled with chylous and lymphatic fluids ${ }^{3}$.These cyst are considered to be originated from lymphatic leaking of an efferent communication with the lymphatic system and they are most often unilocular and solitary ${ }^{3}$.

Mesenteric cyst are most frequent in the second decade of life but are known to occur in the first decade as well ${ }^{3}$. The clinical presentation is not characteristic and in addition the preoperative imaging although suggestive but not diagnostic. In

a. Dr. Shahanaj Sharmin, Associate Professor (Obs \&Gynae), Chattagram Maa-O-Shishu Hospital Medical College.

b. Prof Didarul Alam, Head of Department of Paediatric ICU, Chattagram Maa-O-Shishu Hospital Medical College.

c. Dr. Md. Moklesur Rahman, Associate Professor, General Surgery, Chittagong Medical College, Chittagong.

d. Dr. Seheli Nargis, Agrabad Maternal \& Child Health Family Planning, Chittagong.

Address of Correspondence: Dr. Shahanaj Sharmin, Assistant Professor of Gynae \& Obs., Bangabandhu Memorial Hospital, University of Science and Technology Chittagong, E-mail: sharmin35cmc@gmail.com, Mobile No.+8801747051592

Received: 6 August, 2017

Accepted: 15 November, 2018 abdominal cavity containing dense echogenic debris within, with no obvious flow in the wall-suggestive of twisted chocolate cyst. Exploration of the abdomen revealed a solitary cyst containing milky fluid about $55 \mathrm{~cm}$ distal to dudenojejunal flexure and twisted cyanosed coils of intestine. Histopathology of the excised cyst was consistent with chylolymphaticus cyst (Mesenteric cyst)

Keywords : Laparotomy, Mesenteric Cyst, Chylolymphatic cyst.

(J Bangladesh Coll Phys Surg 2019; 37: 83-85)

DOI: https://doi.org/10.3329/jbcps.v37i2.40565

most cases, the diagnosis is confirmed after surgical exploration.

\section{Case Report:}

This is a case report of 18 yrs girl, who presented with diffuse abdominal pain for 14 days \& lump in the lower abdomen. Physical examination revealed a lump in lower abdomen includes left iliac fossa and umbilical region which is tense, tender slightly mobile and about $18-20 \mathrm{~cm}$ size. Baseline investigations and renal function tests of the patient were normal. Serum amylase, CA-15 and intravenous urogram were also normal.

Ultrasound revealed large cystic lesion ( $12 \times 10.8$ $\times 11.4 \mathrm{~cm}$; Vol- $773 \mathrm{cc})$ is seen in lower abdomen, containing dense echogenic debris within, with no obviousflow in the wall. Left ovary could not be isolated - suggestive of twisted chocolate cyst.

Following requisite investigations an exploration laparotomy was undertaken and revealed a huge cyst $55 \mathrm{~cm}$ distal to dudenojejunal flexure abutting the jejunal mesentry \& twisted with cyanosed coils of intestinecontain milky fluid (FIGURE 2,3). With the help of general surgeon content of the cyst aspirated then the major portion of the cyst have been dissected, but one portion abutting on the intestine on a major blood vessels seems to be risky to remove, this portion left and its lining destroyed by careful diathermy. 


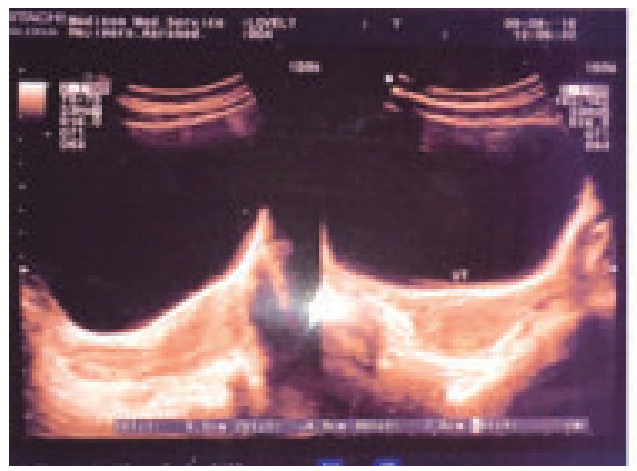

(a)

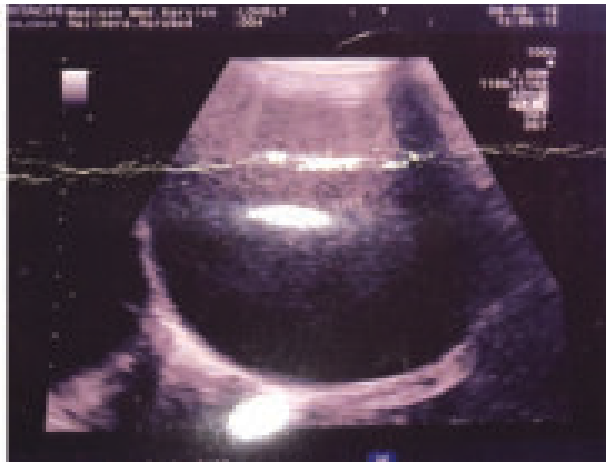

(b)

Fig.-1: USG revealed large cystic lesion

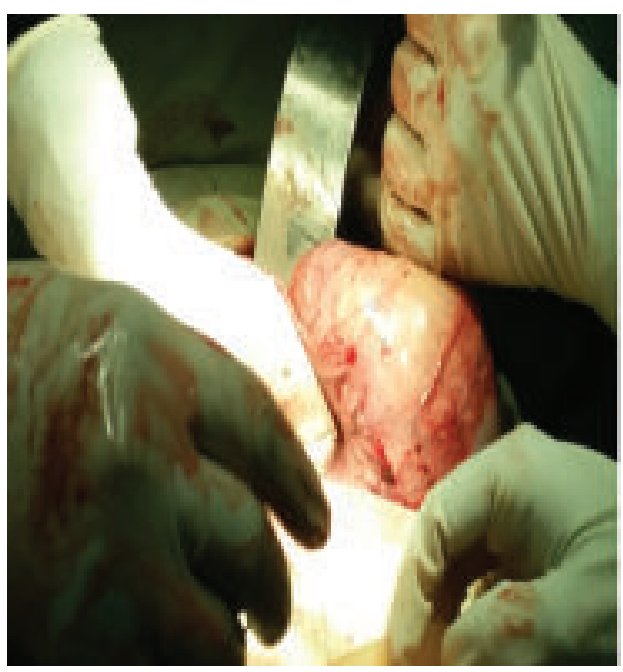

(a)

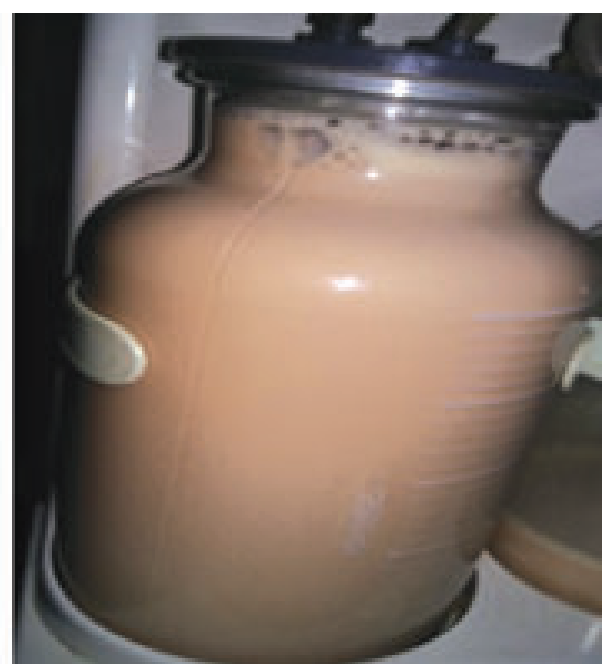

(b)

Fig.-2: .(a) Intra operative cyst identification, (b) The cyst contained

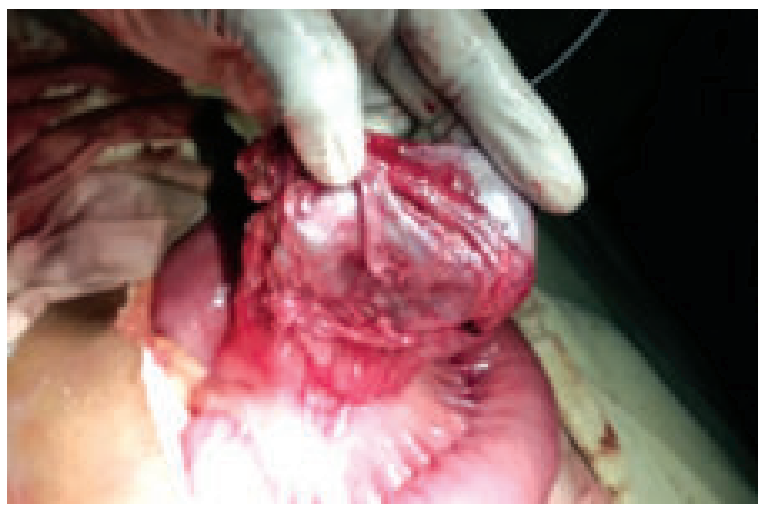

Fig.-3: After aspiration

The diagnosis was confirmed on histopathology which revealed a cyst wall line with endothelium having lymphoid aggregate and foam cells.

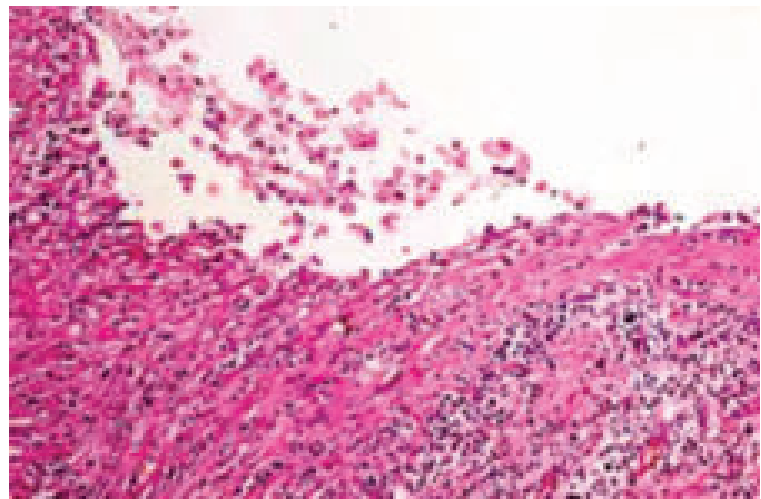

Fig.-4: Histopathology

Post-operative period was uneventful. After one month of follow up the patient was found to be well, having no complication. 


\section{Discussion:}

Mesenteric cyst were first described in the $16^{\text {th }}$ century ${ }^{4}$. They are one of the rarest abdominal tumoursand the incidence ranges from 1: 100000 to 1: 250000 admission to hospital ${ }^{5}$. Mesenteric cyst classified into four group based on etiology; Embryonic or Developmental, Traumatic or Acquired; Neoplastic and Infective or Degenerative ${ }^{6}$. Based on the contents of the cyst, the mesenteric cyst can be divided into Serous, Chylous, Hemorrhagic and Chylolymphatic cyst. The Chylolymphatic cyst means contain both Chyle and Lymph. The accumulation of chyle and lymph is considered to be the result of an imbalance between the inflow and outflow of fluid ${ }^{7}$. The cyst may be asymptomatic or may manifest with abdominal pain, abdominal lump or intestinal obstruction $^{8}$. Our patient was symptomatic with mild and long standing abdominal pain. The definitive diagnosis of these lesions is difficult prior to surgical exploration because there are no pathognomonic symptoms or characteristic imaging findings. Abdominal radiograph are usually non-contributory, however, it may reveal dilated bowel loops with air fluid in the very rare cases with intestinal obstruction which may result from compression of the adjacent bowel or by mesenteric volvulus ${ }^{9}$.

The diagnosis may be suggested by an ultrasound of the abdomen, which may reveal a cystic lesion in relation to the bowel loops away from the adjacent viscera. A fluid-fluid level has been reported as a characteristic finding of these cyst which result from an upper fluid level due to the chyle and a lower fluid level due to the heavier lymph ${ }^{10}$.

Bariumstudies are now only of historical.CT scan demonstrates the fluid attenuation of the lesion and its relationship with the adjacent visera. A characteristic chyle-lymp fluid level has also been described ${ }^{11}$.

However in the present series ultrasonography revealed twisted ovarian tumour. Following laparotomy showed chylolymphaticus variety of mesenteric cyst. When after aspiration of about half the contents of the cyst, the major portion of the cyst have been dissected free, but one portion abutting on the intestine on a major blood vessel seems to dangerous to remove, this portion can be left attached and its lining destroyed by careful diathermy. Post operative period was uneventful and the patient recovered well. The specimen was sent for histopathological examination, which revealed multiloculated cyst lined with single layer of endothelium and contained chylon fluid and lymph.

\section{Conclusion:}

Chylolymphatic cyst is a rare type of mesenteric cyst.In most of the cases the diagnosis is confirmed following surgical exploration and removal of the cyst. Malignant transformation is rare and surgical removal of these cysts is usually curative.

\section{References:}

1. Engel S, Clagett OT, Harrison Jr. Chylous cyst of the abdomen. Surgery 1961, 50:593-599.

2. Gupta AR, Nanabati RN, FernandezAR, Kalgutkar A, Nathani R, Deshmukh SS. Chylous mesenteric cyst: an unusual case of neonatal intestinal obstruction. Indian Paediatrics 1992,29(4):511-513.

3. Mann CV. The peritoneum, omentum, mesentery and retroperitoneal space. In : Mann CV, Russell RC, Williams NS, editors. Bailey and Love's short practice of surgery' $22^{\text {nd }}$ ed. Chapman and Hall: London1995;764-780.

4. Monihan B.G. Mesenteric cysts. Ann Surg. 1897;26:1-30. [PMC free article] [PubMed].

5. Liew S.C, Glen D.C, Storey D.W. Mesenteric cyst. Aust N Z J surg. 1994;64:741-744.[PubMed]

6. Beahrs OH, Judd ES Jr, Dockerty MB: Chylous cysts of the abdomen. The surgical Clinics of North America 1950,30(4): 1081-1096.

7. Engel S, Clagett O.T,Harrison Eg. Chylous cysts of the abdomen. Surgery. 1961;50:593-599.[PubMed]

8. Rattan K.N, Nair V.J, Pathak M.Kumar S. paediatric chylolymphatic mesenteric cyst- a separate entity from cystic lymphangioma: a case series. J Med Case Rep. 2009;3:111.[PubMed]

9. Y a Boog, S.S Hussain, M Elmy. Giant Chylolymphatic mesenteric cyst and its successful enucleation: A case report.Int J. Surg case Rep. 2014;5(8):469-470.

10. Fujita N, Noda Y, Kobayashi G, Kimura K, Watanabe H, Masu K et al. Chylous cyst of the mesentery: USG and CT diagnosis Abdomen imaging. 1995;20:259-261.

11. Philips gw, Senapati A, Young AE. Chylolymphatic mesenteric cyst: A diagnostic appearance on computed tomography. Br J Radiol. 1988;61:413-414. 